\title{
STUDY OF MAIZE PLANTS EFFECTS IN THE RETRIEVAL OF SOIL MOISTURE USING THE INTERFERENCE PATTERN GNSS-R TECHNIQUE
}

\author{
N. Rodriguez-Alvarez ${ }^{\S}$, X. Bosch-Lluis ${ }^{\S}$, R. Acevo ${ }^{\S}$, A. Aguasca $^{\S}$, A. Camps ${ }^{\S \rho}$, M. Vall-llossera ${ }^{\S \rho}$, I. Ramos-Perez ${ }^{\S}$, \\ E. Valencia ${ }^{\S}$ \\ ${ }^{\S}$ Remote Sensing Lab, Dept.Teoria del Senyal i Comunicacions, Building D3, Universitat Politècnica de \\ Catalunya and IEEC CRAE/UPC, 08034 Barcelona, Spain. \\ ${ }^{\rho}$ SMOS Barcelona Expert Centre. Pg. Marítim de la Barceloneta 37-49, 08003 Barcelona, Spain \\ Tel.+34+934017362, E-mail: nereida@tsc.upc.edu
}

\begin{abstract}
The use of Global Navigation Satellite Signals Reflections (GNSS-R) techniques to retrieve geophysical parameters from surfaces has been increased in the recent years. These techniques have resulted in suitable tools to obtain information about the sea state of oceans, which is very useful to improve the ocean salinity retrieval [1-3], and also, information about the soil moisture [4-6] of lands.

The present work focuses on the use of the Interference Pattern Technique (IPT) [7-10], a particular type of GNSS$\mathrm{R}$ technique, to study vegetation-covered soils. The IPT consists mainly of the measurement of the interference pattern between the GPS direct and reflected signals (the interference power), after they impinge over the ensemble soil surface and vegetation layer. The measured interference signal provides information on the soil moisture of the surface and also, on the vegetation height.
\end{abstract}

Index Terms - GNSS-R, Interferometric-pattern, Soil moisture, Vegetation, Growth, Retrieval

\section{INTRODUCTION}

A previous study [10], showed that this kind of retrievals can be performed over wheat and barley fields, where plants reach $60 \mathrm{~cm}$ height and their dominant structure is vertical. This work extends the previous studies to maize-covered fields whose height reaches up to $250 \mathrm{~cm}$ and their structure is mostly vertical, but also due to the long leaves, they have a significant horizontal component, they are density packed, and the vegetation water content is much higher than in the case of wheat. The paper is divided in three main parts. First the theoretical aspects of the IPT measurements over a maize scenario are presented focussing on the simplification of the model implemented to emulate the vegetation layer. Secondly, it is presented the experimental measurements carried out to test the theoretical aspects and the main results achieved. Finally, the conclusions about the suitability of the simplified model and its application to maize planted fields are exposed.

\section{MAIZE EFFECTS THEORETICAL FUNDAMENTALS}

In a previous work [10], a complex model based in Lsystems [11] was used to model trunk and leaves scattering. In the present work a simplification of this model has been performed considering the vegetation layer as a constant layer with an equivalent maize dielectric constant value, using the Matzler model [12], and the resultant dielectric constant value for the mixture plant air, using the Kerr model [13]. Figure 1 shows the main interaction of the GPS signals and the instrument, which is called Soil Moisture Interference-pattern GNSS Observations at L-band (SMIGOL) Reflectometer $[9,10]$.

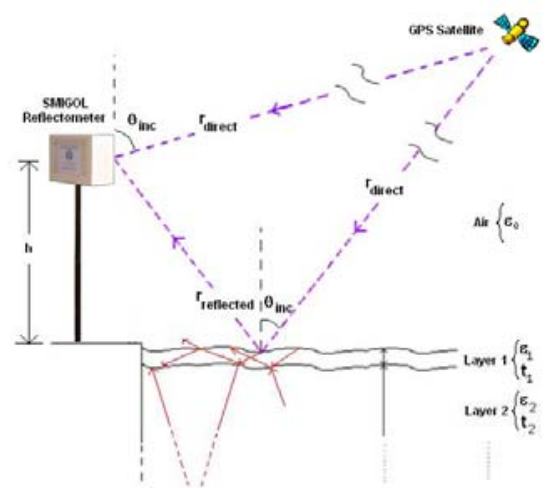

Figure 1. Geometrical configuration of SMIGOL Reflectometer and the GPS signals reflecting over a surface composed of several layers characterized by their dielectric constant (ci), thickness (ti) and the roughness between layers.

Most significant improvements in the theoretical relationships between geophysical parameters and their effects over the interference power are related to the plant height. The algorithms related to soil moisture and topography have also been improved, but their modifications are not as relevant as the height retrieval ones, so they are not explained in more detail than it was in [10].

As previously observed in [10], vegetation height is directly linked to the number of notches and their positions 
in the interference power measured. A notch is defined as a minimum amplitude oscillation in the interference power. An example of notches present in the interference power can be seen at Fig. 2. After simulating different heights using the simple layer model the result obtained for the theoretical evolution of notches is the one that can be observed in Fig. 3.

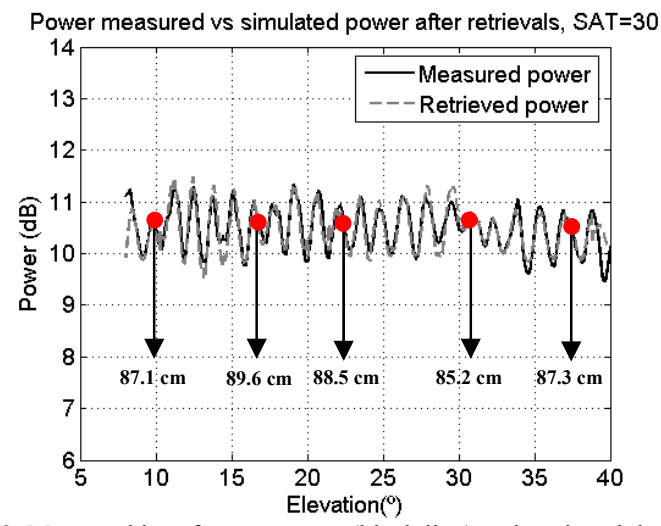

Figure 2. Measured interference power (black line) and retrieved theoretical power (grey-dashed line) for one satellite measurement on June $8^{\text {th }}$.

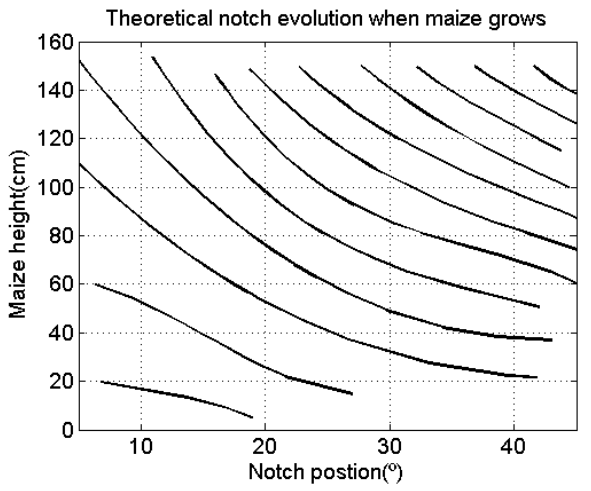

Figure 3. Vegetation height as a function of the incidence angle where notches take place.

Compared with the previous result [10], where the evolution of notches for wheat using a complex electromagnetic model to emulate the scattering was presented, the present study reaches higher vegetation heights $(150 \mathrm{~cm})$, and a more complete analysis will be presented at the conference (up to $250 \mathrm{~cm}$ ). The important result is that for the first $60 \mathrm{~cm}$ both [10] and the present simplified model are equivalent, therefore the simplified model can be used for most crops.

\section{MAIZE FIELD EXPERIMENT}

The SMIGOL-Reflectometer $[9,10]$ has been deployed in a field campaign over a maize field, Fig. 4, at Palau d'Anglesola, Lleida, Spain, since March 2010 and will last up to October 2010, when maize will be harvested. In that way it is covering different growth stages of the maize, from no vegetation up to $230-250 \mathrm{~cm}$ vegetation height, including the dry up process of the maize.

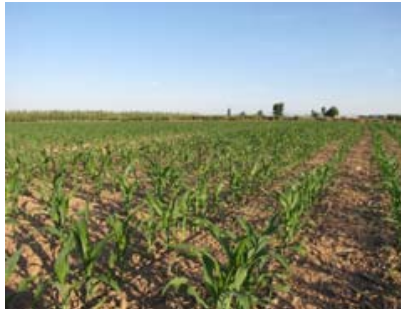

(a) (b)

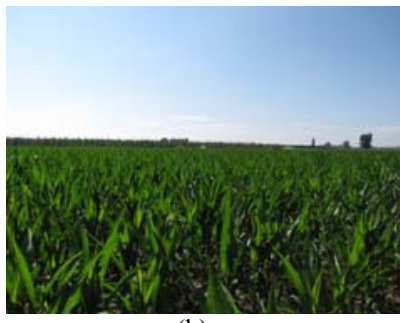

Figure 4. Maize field experiment at Palau d'Anglesola, Lleida, Spain. Photographs correspond to May $30^{\text {th }}$ (40 cm maize height) and June, $19^{\text {th }}$ (135 cm maize height)

Figure 5 shows the main ground-truth of the field experiment.

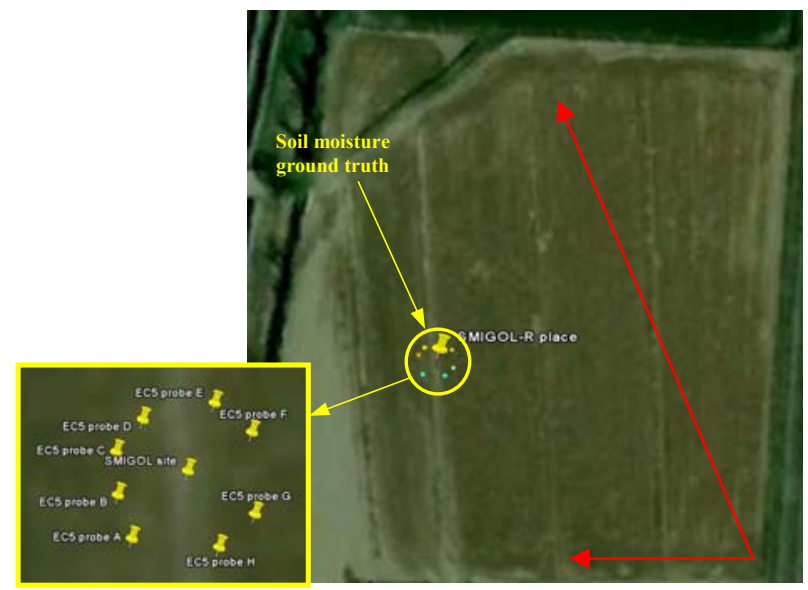

Figure 5. Palau d'Anglesola field experiment over maize. The soil moisture probes ECH2O-EC5 are located around the SMIGOL-Reflectometer. The main inclination directions of the field are shown using red arrows.

The soil moisture of the field has been monitorized using ECH2O-EC5 soil moisture probes [14], which have been located around the SMIGOL-Reflectometer to clearly see the tendency of the water in the field. Probes A, C, E and $\mathrm{G}$ are located at $5 \mathrm{~cm}$ depth while probes $\mathrm{B}, \mathrm{D}, \mathrm{F}$ and $\mathrm{H}$ are located at $20 \mathrm{~cm}$ depth. Topography of the field has been defined by the farmer to have two main inclinations, shown in Fig.5 with red arrows, and the maximum topography difference is $40 \mathrm{~cm}$.

Topography, soil moisture and vegetation height retrievals have been applied to the measurements. Figure 2 shows the satellite 30 interference power measured by the SMIGOL-Reflectometer on June $8^{\text {th }}, 2010$, DoY $=159$, and the simulated interference power, which are in excellent agreement. As it can be seen in Fig. 2, after applying the three retrieval algorithms, the measured and the retrieved powers are very close. Furthermore the height retrieved for each one of the notches found is specified. 
After processing the measurements achieved during the field experiment some results have been achieved for the topography, soil moisture and vegetation height.

In Fig. 6 the topography retrieval is shown.

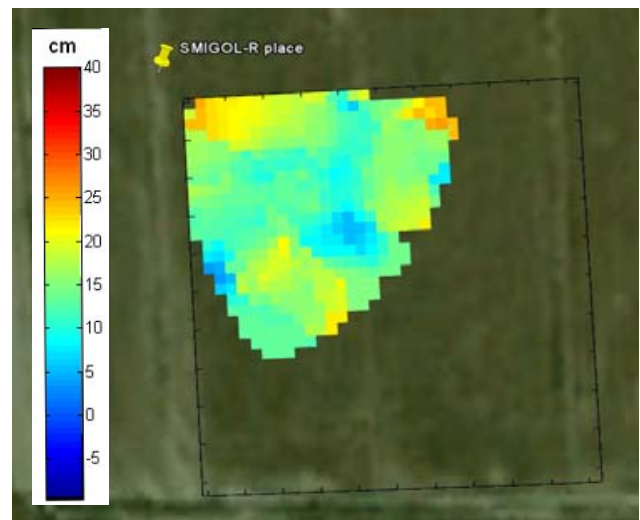

Figure 6. Topography retrieval achieved by processing the SMIGOLReflectometer measurements.

This result has been achieved averaging 6 days of data, approximately 20 satellites information. The maximum difference is near to $20 \mathrm{~cm}$ which is coherent with the maximum difference of the field informed by the farmer.

In Fig. 7 the main result for the vegetation height retrieval is shown.

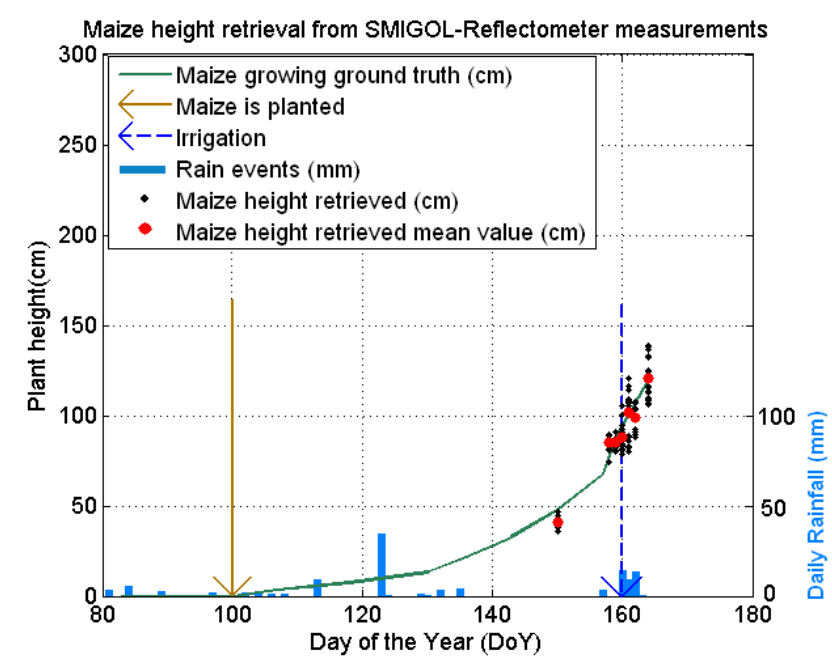

Figure 7. Maize plant height retrieval achieved by processing the SMIGOL-Reflectometer measurements.

The maize growing presented (solid green line) does not correspond to the whole growing process (on-going), but extended results will be presented at the conference, with more updated data from the field experiment. At the present moment maize plant is $120 \mathrm{~cm}$ high. It was planted (brown arrow) on DoY 100 and was irrigated (blue dashed arrow) on DoY 160. Furthermore heavy rain events (blue bars) occurred on DoY 160 and 161. Ground truth about rain events has been achieved from the Servei Meteorologic de Catalunya web page [15] thanks to the closeness $(720 \mathrm{~m})$ of the Poal meteorological station to the field experiment. As it can be seen, in Fig. 7, the retrieved values using the SMIGOL-Reflectometer measurements are highly correlated with the maize growing. The measurements mean value agrees with the ground truth, obtained randomly selecting maize plants. Table I summarizes the vegetation height results.

Table I. Vegetation height results

\begin{tabular}{|c|c|c|c|}
\hline $\begin{array}{c}\text { Height / } \\
\text { DoY }\end{array}$ & $\begin{array}{c}\text { Ground-truth } \\
\text { mean value }\end{array}$ & $\begin{array}{c}\text { SMIGOL-Reflect } \\
\text { measurements }\end{array}$ & Error \\
\hline 150 & $47.50 \mathrm{~cm}$ & $41.27 \mathrm{~cm}$ & $6.23 \mathrm{~cm}$ \\
\hline 158 & $77.50 \mathrm{~cm}$ & $85.13 \mathrm{~cm}$ & $7.63 \mathrm{~cm}$ \\
\hline 159 & $88.33 \mathrm{~cm}$ & $84.99 \mathrm{~cm}$ & $3.34 \mathrm{~cm}$ \\
\hline 160 & $94.65 \mathrm{~cm}$ & $87.86 \mathrm{~cm}$ & $6.79 \mathrm{~cm}$ \\
\hline 161 & $101.05 \mathrm{~cm}$ & $101.75 \mathrm{~cm}$ & $0.70 \mathrm{~cm}$ \\
\hline 162 & $107.33 \mathrm{~cm}$ & $98.65 \mathrm{~cm}$ & $8.68 \mathrm{~cm}$ \\
\hline 164 & $119.80 \mathrm{~cm}$ & $120.44 \mathrm{~cm}$ & $0.64 \mathrm{~cm}$ \\
\hline
\end{tabular}

Figures 8 and 9 show the soil moisture retrievals.

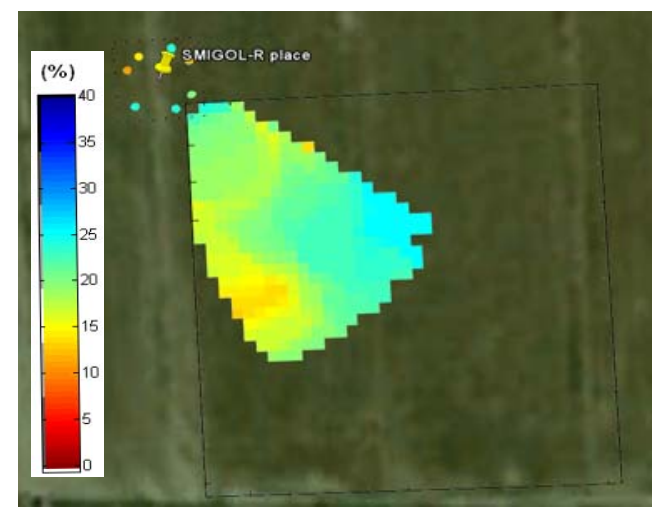

Figure 8 . Soil moisture retrieval achieved by processing the SMIGOLReflectometer measurements for day June $8^{\text {th }}, \mathrm{DoY}=159$, prior to heavy rain and irrigation.

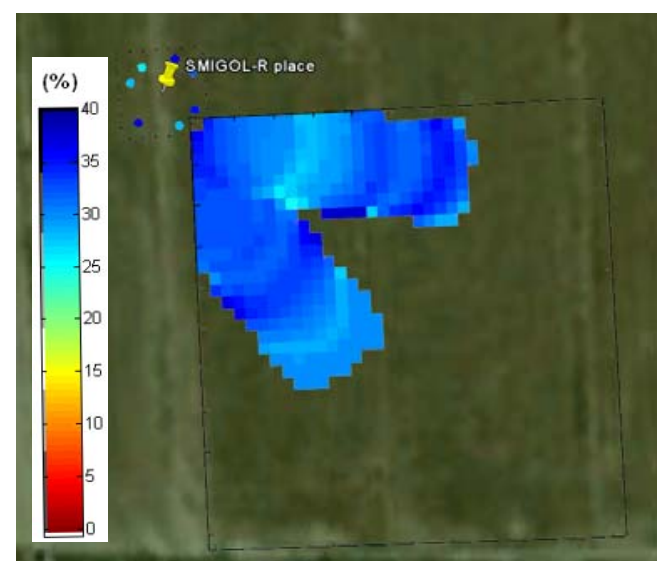

Figure 9. Soil moisture retrieval achieved by processing the SMIGOLReflectometer measurements for day June $10^{\text {th }}$, DoY $=161$, after heavy rain and irrigation. 
Figures 8 and 9 show the results achieved after processing the satellite data available for days June $8^{\text {th }}$ and $10^{\text {th }}$, respectively. In table II the ground-truth measurements and the SMIGOL-Reflectometer measurements are summarized.

Table II. Soil moisture retrieval results.

\begin{tabular}{|c|c|c|c|}
\hline $\begin{array}{c}\text { Soil moisture } \\
\text { \ DoY }\end{array}$ & $\begin{array}{c}\text { EC5-Probe G } \\
\text { (5 cm depth) }\end{array}$ & $\begin{array}{c}\text { EC5-Probe H } \\
(20 \mathrm{~cm} \text { depth })\end{array}$ & $\begin{array}{c}\text { SMIGOL-Reflect. } \\
\text { Measurements }\end{array}$ \\
\hline 159 & $20 \%$ & $24 \%$ & $23.4 \%, 24.2 \%$ \\
\hline 161 & $35 \%$ & $28 \%$ & $34.2 \%, 35.9 \%$ \\
\hline
\end{tabular}

In one hand, for DoY 159 , the error is $[0.2-0.6] \%$ respect to the $20 \mathrm{~cm}$ depth probe and [3.4-4.2] \% respect to the $5 \mathrm{~cm}$ depth probe. In the other hand, for DoY 161, the error is $[0.8-0.9] \%$ respect to the $5 \mathrm{~cm}$ depth probe and [6.2 - 7.9] \% respect to the $20 \mathrm{~cm}$ depth probe. When soils are wet the retrieved value is closer to the surface ground truth and when soils are dryer the retrieved values are near to the $20 \mathrm{~cm}$ depth values.

\section{CONCLUSIONS}

The simplification of the previous developed model for vegetation scenarios performed in [10] into a simple layered model including only information about plant dielectric constant, has been tested and good result has been achieved for the three retrievals performed, topography, vegetation height and soil moisture. The field experiment performed at Palau d'Anglesola, Lleida, Spain over a maize field has allowed testing not only the simplification of the model but also the fact that the Interference Pattern Technique also works over maize plants, which have clear vertical and horizontal components in the growing structure.

\section{ACKNOWLEDGEMENT}

This work, conducted as part of the award "Passive Advanced Unit (PAU): A Hybrid L-band Radiometer, GNSS-Reflectometer and IR-Radiometer for Passive Remote Sensing of the Ocean" made under the European Heads of Research Councils and European Science Foundation EURYI (European Young Investigator) Awards scheme in 2004, was supported by funds from the Participating Organizations of EURYI and the EC Sixth Framework Program. Also by funds from the Plan Nacional del Espacio of the Spanish Ministry in the frame of the project with reference ESP2007-65567-C04-02. And also by funds from the project with reference AYA2008-05906C02-01/ESP

\section{REFERENCES}

[1] Zavorotny, V.U. and Voronovich, A.G. "Scattering of GPS signals from the ocean with wind remote sensing application," IEEE Transactions on Geoscience and Remote Sensing, vol. 35 (3), pp. 951-964, 2000
[2] Rius, A., J.M. Aparicio, E. Cardellach, M. Martín-Neira, and B. Chapron, "Sea surface state measured using GPS reflected signals," Geophysical Research Letters, Vol. 29 (23), pp. 2122, December 2002.

[3] Marchan-Hernandez, J.F., N. Rodríguez-Álvarez, A. Camps, X. Bosch-Lluis, and I. Ramos-Perez, "Correction of the Sea State Impact in the L-band Brightness Temperature by Means of DelayDoppler Maps of Global Navigation Satellite Signals Reflected over the Sea Surface," IEEE Transactions on Geoscience and Remote Sensing, Vol. 46 (10), part 1, pp. 2914 - 2923, October 2008.

[4] Masters, D., V. Zavorotny, S. Katzberg and W. Emery, "GPS signal scattering from land for moisture content determination," Proceedings of the IEEE International Geoscience and Remote Sensing Symposium 2000, Vol.7 pp. 3090-3092, July 24 - 28, 2000, Honolulu, HI, USA.

[5] Gleason, S., "Detecting Bistatically Reflected GPS Signals from Low Earth Orbit Over Land Surfaces," Proceedings of IEEE International Geoscience and Remote Sensing Symposium 2006, pp. 3086 - 3089, July 31 - Aug. 4 2006, Denver, Colorado.

[6] Masters, D, "Surface Remote Sensing Applications of GNSS Bistatic Radar: Soil Moisture and Aircraft Altimetry," Ph. D. dissertation, University of Colorado, 2004.

[7] Kavak, A., G. Xu, , and W.J. Vogel, "GPS multipath fade measurements to determine L-band ground reflectivity propierties," Proceedings of NAPEX XX, pp. 257-263, 1996.

[8] Kavak, A., W.J. Vogel, and G. Xu, "Using GPS to measure ground complex permittivity," Electronic Letters, vol. 34 (3), pp. 254-255, February 1998.

[9] Rodriguez-Alvarez, N., Bosch-Lluis, X., Camps, A., Vallllossera, M., Valencia, E., Marchan-Hernandez, J.F., Ramos-Perez, I.; "Soil moisture retrieval using GNSS-R techniques: experimental results over a bare soil field," IEEE Transactions on Geoscience and Remote Sensing, Vol. 47 (11), pp. 245-248, November 2009.

[10] Rodriguez-Alvarez, N., Camps, A., Vall-Llossera, M., BoschLluis, X., Monerrris, A., Ramos-Perez, I., Valencia, E., MarchanHernandez, J.F., Martinez-Fernandez,J., Baroncini-Turricchia, G., Pérez-Gutiérrez C., Sánchez, N., "Land Geophysical Parameters Retrieval Using The Interference Pattern GNSS-R Technique" IEEE Transactions on Geoscience and Remote Sensing, DOI: 10.1109/TGRS.2010.2049023

[11] Salomaa, A. and Rozenberg, G. "The mathematical theory of L systems," Pure and applied mathematics, a series of monographs and textbooks. New York: Academic Press, 1980.

[12] Matzler C. and Sume A., "Microwave radiometry of leaves," Microwave

Radiometry and Remote Sensing Applications, P. Pampaloni, Ed. Utrecht, The Netherlands: VSP, 1989, pp. 133-148.

[13] Kerr Y. H. and Njoku E.G., "A Semiempirical Model For Interpreting Microwave Emission From Semiarid Land Surfaces as Seen From Space" IEEE Transactions on Geoscience and Remote Sensing, Vol. 28 (3), pp. 245-248, May 1990.

[14] Soil Moisture Sensor.

http://www.decagon.com/ag research/soil/ec5.php

[15]Servei Meteorològic de catalunya.

http://www.meteo.cat/mediamb_xemec/servmet/marcs/marc_dades html 